ilies: Gramineæ, Compositæ, Chenopodiaceæ, Amaranthaceæ, Plantaginaceæ, Polygonaceæ, Betulaceæ, Fagaceæ, Ulmaceæ, Moraceæ, Juglandaceæ, Salicaceæ, Aceraceæ and Oleaceæ.

If to these considerations we add the differential susceptibilities of patients to various types of airborne pollen, the immense variation in local occurrence of the species concerned, and their various times of flowering, it will be apparent how large and complex a field of botanical inquiry lies behind the scientific study of the causes of hay-fever. Such study has of recent years made great progress in the United States, and one of the foremost research workers on pollen characterization and identification, Dr. R. P. Wodehouse, has now published a useful and timely summary of present knowledge of hay-fever conditions in that country.

An introductory chapter explains the origin of airborme pollen and describes the chief methods now employed in estimating the pollen content of the air, filtration, the air-centrifuge, and gravitational settling, combined with microscopic identification. It is interesting to have the first tentative estimates of the minimal pollen doses which will produce hayfever symptoms. For the ragweed (Ambrosia spp.) this appears to correspond with a pollen frequency of about 200 grains per cubic yard of air, or a daily inhalation of about 4,000 grains.

Subsequent chapters give brief descriptions of all the species now recognized as concerned, or possibly concerned, with hay-fever in the United States, with accounts of form, habitat and flowering season, illustrations of the plants, and full description and illustration of the pollen grains.

Lastly there follows a valuable analysis of all the recorded data for the United States treated on a basis of twelve geographical regions, for each of which there is given a comprehensive chart illustrating the frequeney and flowering season of all the hay-fever plants. From this information both clinician and botanist will derive much help. We can see at a glance bow in the north-eastern States there are three phases of hay-fever in the year-the unimportant early spring phase of tree pollen, the important early summer grass pollen phase, and the very important late summer ragweed pollen phase. This contrasts strongly with conditions in the southern States, where the long growing season gives many continuous months of hay-fever conditions to which many pollen types contribute. In this section we find also discussed how the weediness of undeveloped building estates makes for bad hay-fever conditions, and how forest cover and maritime situation offer good conditions suitable for hay-fever resorts.

It is very striking to the English botanist to observe that most of the grasses which are serious causes of hay-fever in the United States are those introduced from Europe, such as Anthoxanthum odoratum, Poa pratensis, Phleum pratense, Agrostis alba and Dactylis glomerata, while with them is associated Plantago lanceolata. Presumably the reason for this is that these are all weeds or cultivated grasses now abundant around the big population centres which are comparatively out of reach of pollen borne by the wind from the prairies. Otherwise one would not expect the native prairie grasses to be so overweighted in effect.

It is to be hoped that this book will encourage much similar work, not only in the United States, but also in Great Britain, where hitherto only Hyde and Williams have made significant headway in this direction.

\section{METHODS IN CLIMATOLOGY}

\section{Methods in Climatology}

By Victor Conrad. Pp. xx+228. (Cambridge, Mass. : Harvard University Press; London : Oxford University Press, 1944.) $2 \hat{z} s, 6 d$. net.

$I^{N}$ $\mathrm{N}$ this book, Dr. Victor Conrad, formerly head of the Austrian Meteorological Service, and now research associate in climatology in Harvard University, gives an outline of methods of treatment of observations, as distinguished from results of the treatment.

The book is in four parts, the first dealing with the general methods of statistical diseussion, including the evaluation of frequency distributions, the mean, median, mode, etc., the fitting of curves to numerical data, the smoothing of data, and the essential formulæ of harmonic analysis.

The second part deals with the representation of characteristic features of different elements. Thus under the heading of temperature we find the discus. sion of the relation of the mean of two or three observations made at standard times to the 'true mean', which is the mean of 24-hourly observations, and the evaluation of spells of weather which satisfy certain conditions. Rather similar technique is applied later to rainfall measurements. The methods of evaluating resultant wind velocity from records of the velocity and direction, and the resultant wind direction from the frequencies of the directions alone, are discussed in a separate chapter. All these topics are relatively simple and could perhaps have been treated more briefly.

While there are frequent references to original papers, the author now and again fails to explain an important point. For example, on p. 111 he gives formulæ for the evaluation of the drying power of the air, the effect of the wind speed, $v$, being represented by a factor $F(v)$. A table of values of $F(v)$ is given for a wide range of values of $v$, presumably from a paper by Knoche. The reader would have profited from a hint as to the form of the function $F(v)$, particularly in view of the fact that a few pages later, in discussing cooling power of the air over a wet surface, the author gives a very different function of $v$ in his equations.

The third part of the book deals with methods of spatial comparison. Methods of testing relative homogeneity of observations, and of the reduction of climatological averages to a uniform period, are briefly treated. Formulæ for computation of the coefficient of correlation, and of the regression coefficients, are given later. Here the reviewer felt that emphasis should have been laid on the practical forms for computation, which are $r=\Sigma x y /\left\{\Sigma x^{2} \cdot \Sigma y^{2}\right\}^{\frac{1}{2}}$ and $b=\Sigma x y / \Sigma x^{2}$ respectively, and not $r=\Sigma x y / n \sigma_{x} \sigma_{y}$ and $b=r \sigma_{y} / \sigma_{x}$. The methods of anomalies, the use of wind roses and stream-lines are briefly discussed.

The fourth part deals with climatography, or the presentation of a complete picture of the climate of a region. This part is of interest in that it brings into prominence a number of features of climate which are frequently overlooked; but it does not suffciently emphasize the fact that a satisfying description of a climate should deal, not only with the monthly means over a period, but also with the variability from the mean.

This book, which is in general simple in its treatment of the questions discussed, will be a help to many a beginner in the subject. 